\title{
Thermal and structural analysis of germanate glass and thin films co-doped with silver nanoparticles and rare earth ions with insights from visible and Raman spectroscopy ${ }^{\text {s }}$
}

\author{
E.A. Carvalho ${ }^{a}$, A.M. Freitas ${ }^{b}$, G.H. Silva ${ }^{b}$, M.J.V. Bell ${ }^{b}$, L.R.P. Kassab ${ }^{c}$, V. Anjos ${ }^{b, *}$ \\ a Instituto Federal de Educação, Ciência e Tecnologia do Sudeste de Minas Gerais, Campus São João Del Rei, São João Del Rei, MG, Brazil \\ ${ }^{\mathrm{b}}$ Laboratório de Espectroscopia de Materiais, Dep. de Física, Universidade Federal de Juiz de Fora, Juiz de Fora, MG, Brazil \\ ${ }^{\mathrm{c}}$ Laboratório de Tecnologia em Materiais Fotônicos e Optoeletrônicos, Faculdade de Tecnologia de São Paulo, CEETEPS/UNESP, 01124-060 São Paulo, SP, Brazil
}

\section{A R T I C L E I N F O}

\section{Article history:}

Received 1 May 2016

Received in revised form 2 October 2016

Accepted 3 October 2016

Available online 4 October 2016

\section{Keywords:}

Germanate

Rare earths

Nanoparticles

Thermal lens

Thermal diffusivity

Raman scattering

\begin{abstract}
A B S T R A C T
This paper reports on the thermal and optical properties of germanate glasses $\mathrm{GeO}_{2}-\mathrm{PbO}$ co-doped with silver nanoparticles and rare earth ions $\left(\mathrm{Tm}^{3+}, \mathrm{Er}^{3+}\right.$ and $\left.\mathrm{Yb}^{3+}\right)$ with a focus on the thermal diffusivity (D). The presence of rare earth ions and nanoparticles is evidenced by absorption spectra and TEM images, respectively. Additionally, a structural comparison between thin films and bulk glass with the same nominal composition is given. It is found that D increases up to $20 \%$ in samples where nanoparticles are present, although their quantity corresponds only to a volume fraction of $1.7 \%$. Therefore, such enhancement could be associated with the nanoparticles. Nevertheless, a Raman analysis revealed a structural change after the thermal treatment used for the nucleation of the nanoparticles. A decrease in the intensity of the band at $534 \mathrm{~cm}^{-1}$ in the Raman spectra is interpreted as the disruption of the 3-membered rings of the $\mathrm{GeO}_{4}$ tetrahedra. The Raman analysis also revealed the formation of small crystals of $\alpha-\mathrm{GeO}_{2}$ type quartz and the adsorption of carbon dioxide on the surface of the silver nanoparticles inserted in the germanate thin film.
\end{abstract}

(c) 2016 Elsevier B.V. All rights reserved.

\section{Introduction}

Germanate glass is a suitable material for doping with Rare Earth (RE) ions due to their large transmittance window (from visible to the infrared region) and a low phonon energy $\left(800 \mathrm{~cm}^{-1}\right)$ when compared with silicate glasses $\left(1150 \mathrm{~cm}^{-1}\right)[1,2]$. Vitreous systems with low phonon energy are desirable in order to minimize nonradiative processes, which imply, in another perspective, an increase in the probability of radiative decays. Other properties of the germanate glass matrix are its high refractive index $(\approx 2)$ and a large chemical stability. Recently, the growth of metallic nanoparticles (NP) inside germanate glasses has been achieved by thermal treatment of the samples. It has been verified that the presence of silver and gold NPs contribute to enhanced luminescence efficiency and nonlinear optical improvements [3-8].

The use of new systems in optical devices also depends on the knowledge of their thermal properties that are often crucial for a

\footnotetext{
Selected paper from for IV Encontro Brasileiro de Espectroscopia Raman (EnBraER), in Juiz de Fora, December 06-09, 2015.

* Corresponding author.

E-mail addresses: virgilio@fisica.ufjf.br, virgilio.anjos@gmail.com (V. Anjos).
}

better performance. For example, materials with high thermal diffusivity are required to dissipate heat efficiently in computer processors and lasers. In contrast, materials with low thermal diffusivity are required for thermo-electric devices and thermal barriers, in order to enhance their figures of merit [9]. Moreover, it is also expected that thermal properties should be modified due to the NPs presence. In fact, the thermal diffusivity of materials depends on the size and concentration of the NPs. In the former case, surface effects become prominent when the thermal wavelength is comparable to the size of the NPs. Considering the latter, percolative thermal transport may occur after a critical density. In general, the theory of heat transport of nanoparticles is basically phenomenological which implies that this subject is still a matter of many discussions in the literature [10].

In the present work, $\mathrm{GeO}_{2}-\mathrm{PbO}$ glasses co-doped with $\mathrm{RE}$ ions (Thulium, Erbium and Ytterbium) and silver NPs are investigated via their absorption spectra, transmission electron microscopy (TEM), thermal lens technique and Raman scattering aiming to understand the influence of the silver NPs in the thermal diffusivity. Finally, Raman spectra of a thin germanate film and of the bulk glass with the same composition are compared, searching for structural changes. 


\section{Experimental procedure}

\subsection{Samples production}

The glass samples were prepared by the melting-quenching technique using the following composition: $58.7 \mathrm{GeO}_{2}-41.3 \mathrm{PbO}$ (mol\%). The doping species were $\mathrm{ErO}_{3}$ (0.5 mass fraction\%), $\mathrm{Tm}_{2} \mathrm{O}_{3}$ (0.25 mass fraction\%), $\mathrm{Yb}_{2} \mathrm{O}_{3}$ (3.0 mass fraction\%) and $\mathrm{AgNO}_{3}$ (3.0 mass fraction\%), according to Table 1. A sample without $\mathrm{AgNO}_{3}$ was prepared as reference. The reagents were melted at $1200^{\circ} \mathrm{C}$ in an alumina crucible for $1 \mathrm{~h}$, quenched in a pre-heated brass mold, annealed at $420^{\circ} \mathrm{C}$ for $1 \mathrm{~h}$ and cooled to room temperature inside a furnace to avoid internal stress. After cooling the samples were polished and those with $\mathrm{AgNO}_{3}$ were heattreated at $420^{\circ} \mathrm{C}$ during 2 and $48 \mathrm{~h}$, to nucleate and grow silver nanoparticles.

A lead-germanate film was deposited on a silicon substrate by RF co-sputtering $(13.56 \mathrm{MHz})$, which uses two targets simultaneously inside a vacuum chamber. For the preparation of one target, labeled by GP, the oxide powders $\left(58.7 \mathrm{GeO}_{2}-41.3 \mathrm{PbO}\right)$ were mixed and then submitted to $8 \mathrm{t}$ of uniaxial pressure, followed by synthesis at $750^{\circ} \mathrm{C}$ for $10 \mathrm{~h}$. The second target used was metallic silver, with a purity of $99.99 \%$. Silica substrates were placed at $15 \mathrm{~cm}$ from the target. Before the film deposition, the base pressure was $\sim 1.3 \times 10^{-3} \mathrm{~Pa}$ to minimize the presence of contaminants. During the process, Ar plasma was used at $0.7 \mathrm{~Pa}$ and $50 \mathrm{~W}$ was used as applied rf power maximum. The film containing silver was submitted to a thermal treatment at $420^{\circ} \mathrm{C}$ during $10 \mathrm{~h}$ to induce the growth of metallic nanoparticles.

\subsection{Experimental set-up}

Optical absorption spectra were recorded by a Shimadzu UV1800 spectrometer operating in the wavelength range of $190-1100 \mathrm{~nm}$, with a spectral resolution of $1 \mathrm{~nm}$. A $200 \mathrm{kV}$ TEM from Zeiss was used to determine the size distribution of the nanoparticles. Glass samples were ground down to powder, mixed with distilled water, and partially decanted. The floating part was taken using a metallic screen as sample holder and analyzed by TEM.

Raman spectra were recorded at room temperature with a T64000 Horiba - Jobin Yvon spectrometer coupled to liquid nitrogen cooled CCD. The spectra were collected with the backscattering geometry, with a spectral resolution of $1 \mathrm{~cm}^{-1}$ and were recorded in a polarization $(\mathrm{HH})$ configuration. This means that if one is staring in front of the microscope, the electric field of the incident laser light is oscillating along the left-right direction. The same type of polarization was chosen for the scattered light. The excitation sources were a He - Ne laser emitting at $632.8 \mathrm{~nm}$ with $35 \mathrm{~mW}$ or an Ar laser tuned at $488 \mathrm{~nm}$ with $130 \mathrm{~mW}$, which corresponds to 1 or $5 \mathrm{~mW}$ on the surface of the samples after passing through the microscope, respectively.

A thermal lens $(\mathrm{TL})$ experiment was performed in the dual beam mode-mismatched configuration. Experimental setup and TL theory can be found in previous papers [5,11]. Basically, the TL

Table 1

Details of the doping of the GP glasses.

\begin{tabular}{llllll}
\hline \multirow{2}{*}{ Glass } & \multicolumn{3}{l}{ Doping Species (mass fraction\%) } & Thermal Treatment \\
\cline { 2 - 4 } & $\mathrm{Er}_{2} \mathrm{O}_{3}$ & $\mathrm{Tm}_{2} \mathrm{O}_{3}$ & $\mathrm{Yb}_{2} \mathrm{O}_{3}$ & $\mathrm{AgNO}_{3}$ & \\
\hline GPsAg & 0.5 & 0.25 & 3.0 & - & $420^{\circ} \mathrm{C} / 1 \mathrm{~h}$ \\
GPAg2H & 0.5 & 0.25 & 3.0 & 3.0 & $420^{\circ} \mathrm{C} / 2 \mathrm{~h}$ \\
GPAg48H & 0.5 & 0.25 & 3.0 & 3.0 & $420^{\circ} \mathrm{C} / 48 \mathrm{~h}$ \\
\hline
\end{tabular}

occurs when a high power and Gaussian profile laser, known as excitation laser beam, produces a local heating in the sample that alters the refractive index. As a consequence it causes a variation of the optical path of light in the material. This variation can be detected by a second laser, called probe laser, which has its beam converged or diverged depending on the material.

The temporal evolution of the thermal lens signal $\mathrm{I}(\mathrm{t})$ is given by:

$\mathrm{I}(t)=I(0)\left[1-\frac{\theta}{2} \tan ^{-1}\left(\frac{2 m V}{\left[(1+2 m)^{2}+V^{2}\right] \frac{t_{c}}{2 t}+1+2 m+V^{2}}\right)\right]^{2}$,

where $m=\left(\omega_{p} / \omega_{e}\right)^{2}, V=Z_{1} / Z_{c}$ with $Z_{c} \ll Z_{2}$. $\omega_{p}$ and $\omega_{e}$ are the radius of the waist of the probe and the excitation laser beam in the sample, respectively. $Z_{c}=\left(\pi \omega_{o p}^{2}\right) / \lambda_{p}$ is the confocal distance of the probe beam, $Z_{1}$ is the distance between the probe beam waist and the sample, $Z_{2}$ is the distance between the sample and the photodiode detector, $\omega_{p o}^{2}$ is the minimum probe laser beam radius and $\mathrm{I}(\mathrm{t})=\mathrm{I}(0)$ when the transient time $\mathrm{t}$ or $\theta$ is zero.

In our experimental arrangement, an Argon laser at $514.5 \mathrm{~nm}$ was used as excitation beam and a $\mathrm{He}-\mathrm{Ne}$ laser at $632.8 \mathrm{~nm}$ as a probe beam. The used parameters for the TL configuration were $\mathrm{V}=1.73$ and $\mathrm{m}=21.69$. The excitation and probe beam diameters at the sample were measured with a perfilometer which furnished values of $\omega_{e}=41.7 \mu \mathrm{m}$ and $\omega_{p}=192.5 \mu \mathrm{m}$, respectively.

The amplitude of the thermal lens signal $\theta$ which is a measure of the phase difference between the probe beam at $r=0$ and $r=2 \omega_{e}$ is given by:

$\theta=\frac{P_{\mathrm{abs}}}{K \lambda_{p}} \varphi \frac{d s}{d T}$,

where $\lambda_{p}$ is the probe beam wavelength, $\mathrm{K}$ represents the thermal conductivity, $\varphi$ is the fraction of energy converted into heat and $P_{a b s}$ is the absorbed power, obtained from the relation $P_{a b s}=P_{i n}$ $(1-R)\left[1-\exp \left(-A_{e} L\right)\right]\left[1-R \exp \left(-A_{e} L\right)\right]^{-1}$. $P_{\text {in }}$ is the input power of the excitation beam, $R$ corresponds to the Fresnel reflectivity, $A_{e}$ is the optical absorption coefficient at the excitation wavelength, $\mathrm{L}$ is the sample thickness and ds/dT is the temperature coefficient of the optical path length change of the sample at the probe beam wavelength. In the materials studied, we have considered $\varphi=1$ since no luminescence was observed for the used excitation wavelength. The characteristic time constant, $t_{c}$, is related to the thermal diffusivity, $\mathrm{D}$, through the following equation:

$t_{c}=\frac{\omega_{e}^{2}}{4 D}$

Finally, a fit of Eq. (1) is performed being $t_{c}$ and $\theta$ adjustable parameters. From Eq. (3) the thermal diffusivity is calculated.

\section{Results and discussion}

\subsection{Absorption spectra and microscope images}

The incorporation of RE ions in the glass matrix can be verified by the absorption spectra as shown in Fig. 1 . The emission bands centered at $380,407,490,522,545,654$ and $800 \mathrm{~nm}$ are attributed to the ${ }^{4} \mathrm{I}_{15 / 2} \rightarrow{ }^{4} \mathrm{G}_{11 / 2},{ }^{4} \mathrm{I}_{15 / 2} \rightarrow{ }^{2} \mathrm{H}_{9 / 2},{ }^{4} \mathrm{I}_{15 / 2} \rightarrow{ }^{4} \mathrm{~F}_{7 / 2},{ }^{4} \mathrm{I}_{15 / 2} \rightarrow{ }^{4} \mathrm{H}_{11 / 2}$, ${ }^{4} \mathrm{I}_{15 / 2} \rightarrow{ }^{4} \mathrm{~S}_{3 / 2},{ }^{4} \mathrm{I}_{15 / 2} \rightarrow{ }^{4} \mathrm{~F}_{9 / 2}$ and ${ }^{4} \mathrm{I}_{15 / 2} \rightarrow{ }^{4} \mathrm{I}_{9 / 2}$ transition of $\mathrm{Er}^{3+}$, respectively. The weak absorption band at $\approx 450 \mathrm{~nm}$ is due to the ${ }^{4} \mathrm{I}_{15 / 2} \rightarrow{ }^{4} \mathrm{~F}_{3 / 2}+{ }^{4} \mathrm{~F}_{5 / 2}$ transition. An intense absorption band at $\approx 980 \mathrm{~nm}$, is mainly due to the ${ }^{2} \mathrm{~F}_{7 / 2} \rightarrow{ }^{2} \mathrm{~F}_{5 / 2}$ transition of $\mathrm{Yb}^{3+}$ ions that overlaps with the weaker ${ }^{4} \mathrm{I}_{15 / 2} \rightarrow{ }^{4} \mathrm{I}_{11 / 2}$ transition of the $\mathrm{Er}^{3+}$ ions [12]. The incorporation of $\mathrm{Tm}^{3+}$ ions in the glass matrix can be confirmed by the band at $780 \mathrm{~nm}$, corresponding to the ${ }^{3} \mathrm{H}_{6} \rightarrow{ }^{2}$ $\mathrm{F}_{2}+{ }^{3} \mathrm{~F}_{3}$. 


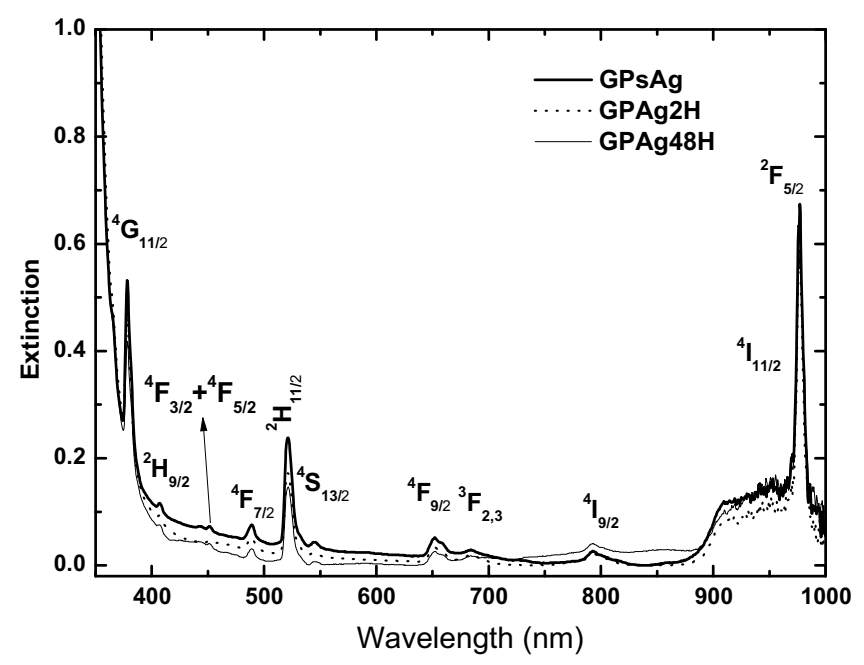

Fig. 1. Absorption spectra of the germanate glasses doped with rare earth ions (Erbium, Ytterbium and Thulium) and silver NPs.

The silver NPs may be detected through an absorption band related to their surface plasmon resonance. In our case, such plasmon is not detected because of the low concentration of NPs. In fact, the fraction volume was estimated as $1.7 \%$, considering that the NPs are spheres with a density equal to the bulk metal density $\left(10.490 \mathrm{~g} / \mathrm{cm}^{3}\right)$. The volume fraction of the particles $\left(\Phi_{v}\right)$ is given by the formula [13]:

$\Phi_{v}=\frac{\Phi_{w} \rho_{m}}{\rho_{p}+\Phi_{w} \rho_{m}-\Phi_{w} \rho_{p}}$,

where $\Phi_{w}$ is the mass fraction of particles dispersed in the matrix, $\rho_{p}$ and $\rho_{m}$ are the densities of the nanoparticles and the base matrix, respectively. The density of the germanate glass was found experimentally by Archimedes' principle, which provided a value of $5.8 \mathrm{~g} / \mathrm{cm}^{3}$.

The existence of the silver NPs was confirmed by TEM images, shown in Fig. 2, which corresponds to glass samples heat-treated at $420^{\circ} \mathrm{C}$ during (a) $2 \mathrm{~h}$ and (b) $48 \mathrm{~h}$. The black spot indicates the formation of nearly spherical silver nanoparticles which increase their size as function of the exposure time. The sample treated during $2 \mathrm{~h}$ presents NPs with average diameters of $5 \mathrm{~nm}$ while the sample submitted to a thermal treatment over $48 \mathrm{~h}$ presents NPs of $10 \mathrm{~nm}$ average diameters (Fig. 3 ).

\subsection{Thermal diffusivity of germanate glasses}

Values of the thermal diffusivity of the germanate glasses were estimated by the Thermal Lens technique performed at different points of the samples. The typical TL signal is shown in Fig. 4. The results indicate a convergent lens-like behavior in the samples since $\mathrm{I}(\mathrm{t})>\mathrm{I}(0)$. This furnishes a positive value of $\mathrm{ds} / \mathrm{dT}$. The thermal diffusivity in the germanate matrix was $2.5 \times 10^{-3} \mathrm{~cm}^{2} / \mathrm{s}$ (Table 2) which is similar to the one found in chalcogenide glasses, but $50 \%$ smaller than in soda lime glasses [14] and 36\% smaller than in tellurite glasses [15].

There is no change in the thermal diffusivity of the germanate glass containing silver NPs submitted to a thermal treatment during $2 \mathrm{~h}$ (Table 2). On the other hand, we have observed an increase of $20 \%$ of this value when the glass was submitted to $48 \mathrm{~h}$ of treatment. From the TEM images, one may verify that the main difference between the two samples is that in the latter the sizes of the NPs are two times larger than the first one, which leads to the conclusion that the nucleation of silver NPS is crucial in the role of increasing the thermal diffusivity. In fact, such behavior was verified in a previous study in colloidal systems with a dispersion of silver or gold nanoparticles [16].

The thermal transport at the nanoscale size is fundamentally different from the one in the macroscale, and it is influenced by several factors: (1) the distribution of heat carrier mean free paths (MFP) in the material, (2) the length scales of the heat sources and (3) the distance over which heat is transported, among others. If the length scale (the distance over which a difference of temperature exists) is much larger than the MFPs, the Fourier's law for diffusive heat works well. In contrast, phonons with long MFPs travel ballistically far from the heat source before they suffer scattering, which leads to a breakdown of the Fourier's law [17].

The cooling dynamics of glass-embedded noble metal nanoparticles have been studied in [18], which highlight the role of interface-mediated processes at the nanoscale regime. According to the authors, the rate in which heat dissipates from a nanoparticle depends both on the thermal resistance at the nanoparticle-glass interface and on heat diffusion in the glass
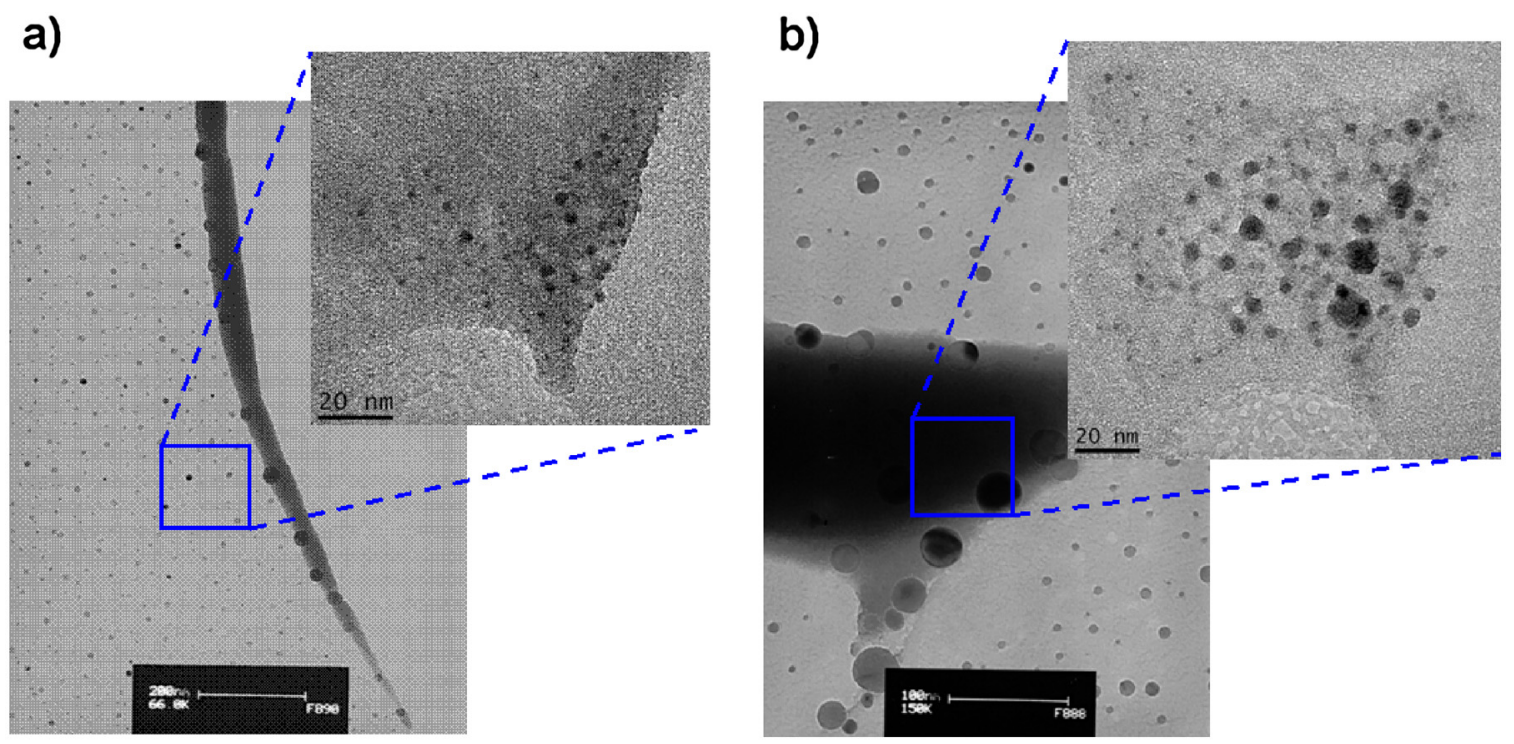

Fig. 2. TEM images for GP heat-treatment for (a) $2 \mathrm{~h}$ and (b) $48 \mathrm{~h}$. 

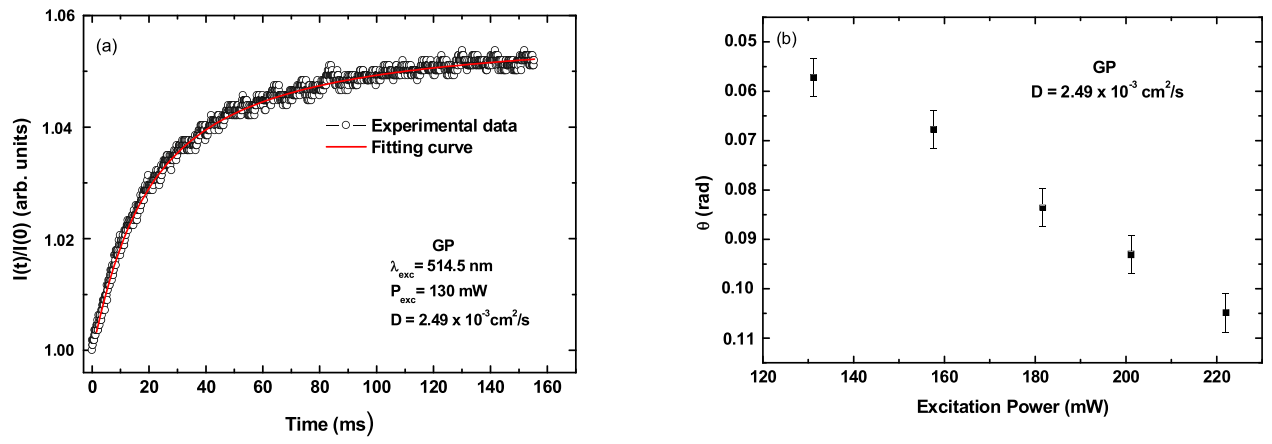

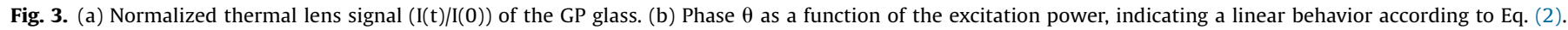

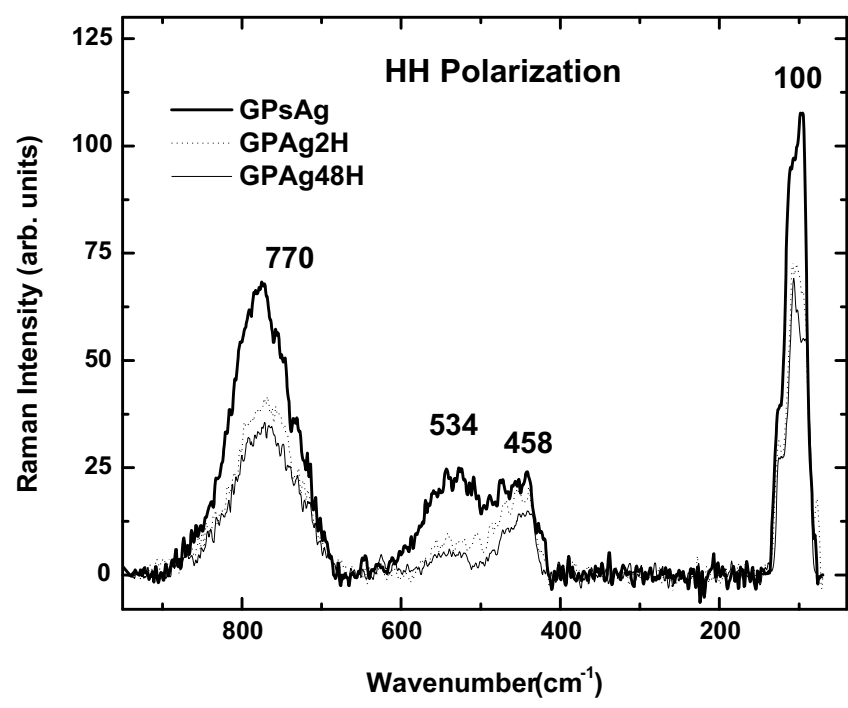

Fig. 4. Raman spectra of the germanate glasses doped with rare earth ions and silver NPs.

Table 2

Thermal diffusivity of the germanate glasses.

\begin{tabular}{ll}
\hline Sample & Diffusivity $\left(x 10^{-3} \mathrm{~cm}^{2} / \mathrm{s}\right)$ \\
\hline GPsAg & $2.5 \pm 0.2$ \\
GPAg2H & $2.5 \pm 0.2$ \\
GPAg48H & $3.0 \pm 0.2$ \\
\hline
\end{tabular}

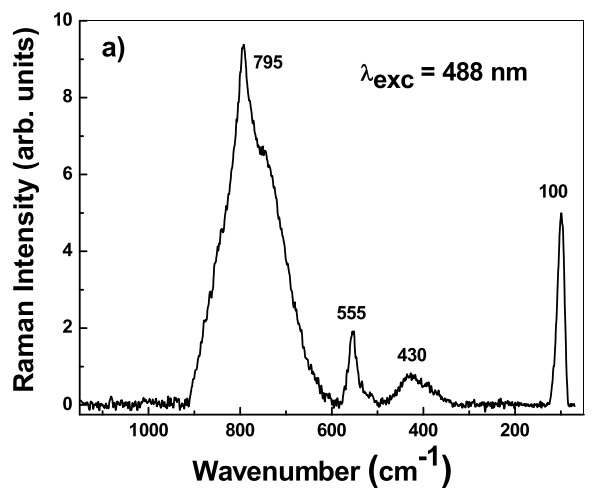

matrix. In short, the nanoscale thermal transport is still elusive even though it has been intensively discussed in the literature [19].

\subsection{Raman spectra of the glass samples}

Fig. 5 exhibits the $\mathrm{HH}$ polarized Raman spectra, which are characterized by two intense bands centered at 100 and $770 \mathrm{~cm}^{-1}$ and two weaker overlapping bands at 458 and $534 \mathrm{~cm}^{-1}$. Depolarized Raman spectra (not shown) only differ from the polarized ones in the low wavenumber region, where the band at $100 \mathrm{~cm}^{-1}$ does not appear. In fact a significant increase in the baseline emerges from the elastic scattering of light.

The bands detected in the polarized Raman spectra are characteristic of the structure of the germanate glasses and do not reveal any traces of RE ions and metallic NPs. The amount of dopant inserted in the samples is too small, which means that the atoms occupy interstitial spaces of the network without breakage of the bounds of the glasses. Therefore, fundamental vibrations of the glasses remain unchanged.

The band at $458 \mathrm{~cm}^{-1}$ is attributed to the asymmetrical stretching vibration of an oxygen atom between two germanium atoms ( $\mathrm{Ge}-\mathrm{O}-\mathrm{Ge}$ bond) and refers to the basic structural unit of germanate glasses. The bands at 100 and $770 \mathrm{~cm}^{-1}$ confirm the incorporation of the lead oxide in the glassy matrix. The former band is associated to $\mathrm{Pb}-\mathrm{O}$ vibrations and the second is the result of symmetric stretching vibration between one germanium atom and a non-bridging oxygen atom $\left(\mathrm{Ge}-\mathrm{O}^{-}\right.$bond) [20]. As it is known, lead oxide acts as a modifier of the glassy structure, breaking the connection of germanium - oxygen creating nonbridging oxygens.

In Fig. 4 the intensity of the band centered at $534 \mathrm{~cm}^{-1}$ decreases (compared to the band at $458 \mathrm{~cm}^{-1}$ ) with the thermal treatment undergone in the sample to induce the growth of the NPs. This band is related to the anomalous behavior shown by

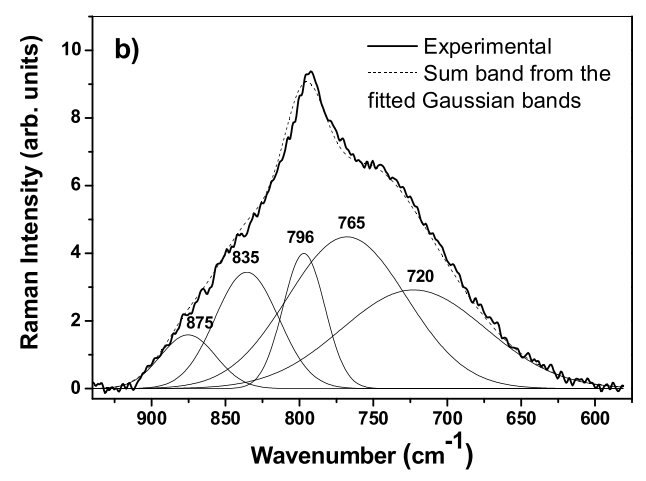

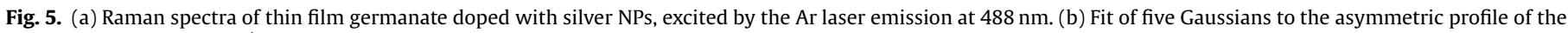
band centered at $800 \mathrm{~cm}^{-1}$ of the Raman spectra shown in (a). 
germanate glasses when modifier oxides are added in the composition [21]. There are two interpretations in the literature to explain this behavior.

The first was proposed jointly by Ivanov and Evstropiev [22] and Murthy and Ip [23]. The authors have suggested that a partial change of the $\mathrm{GeO}_{4}$ tetrahedra to $\mathrm{GeO}_{6}$ octahedra occurs with the increase of the alkali content, altering the germanium coordination number from four to six. Recently, Vijay et al. [24] also verified that the transition metal chromium, like the alkali metals, has a similar effect in the germanate glasses. The octahedral chromium ions act as modifiers and cause disruptions of $\mathrm{Ge}-\mathrm{O}-\mathrm{Ge}$, contributing to the increase of $\mathrm{GeO}_{6}$ structural groups. According to Ribeiro et al. [25], vibrations of the sixfold coordinated germanium atoms are characterized by Raman bands in the region between 600 and $650 \mathrm{~cm}^{-1}$. In our Raman spectra no bands were found in the region $600-700 \mathrm{~cm}^{-1}$.

A second interpretation was given by Henderson and Fleet [26], based on the formation of 3-membered rings of $\mathrm{GeO}_{4}$ tetrahedra in the vicinity of the alkali metal cations, which excludes the possibility of the appearance of $\mathrm{GeO}_{6}$ octahedra. In this case, the Raman spectra would exhibit a characteristic band in the region between 520 and $550 \mathrm{~cm}^{-1}$. Based on our Raman data, we observed a band at $534 \mathrm{~cm}^{-1}$ which led us to attribute its origin to the formation of 3-membered rings of $\mathrm{GeO}_{4}$ tetrahedra.

The reduction of intensity observed in the band at $534 \mathrm{~cm}^{-1}$ of the GPAg2H and GPAg48H samples indicates that the rings of tetrahedral were broken. We attribute this effect to the thermal treatment of the samples once energy is supplied to the bonds, reducing the network connection. Consequently, this structural change affects directly the phonon density of states which may alter the thermal transport. Nevertheless, we do not believe that this disruption would be sufficiently strong to justify an enhancement of $20 \%$ in the thermal diffusivity. The reason is that at room temperature the phonons are of the $\mathrm{THz}$ regime with a very high density of states. Therefore, local network rearrangements will not modify the long range thermal diffusivity.

\subsection{Comparison between Raman spectra of glass and thin films of germanate}

Previously, a detailed study was published analyzing the optical and thermal properties of germanate films doped with silver and gold [27]. Here, we focus only on the Raman spectra of the germanate matrix in the glassy form and in the thin film form when searching for structural changes.

As can be observed in Fig. 4a of the reference [27], the Raman spectrum of GP Ag thin-film is characterized by two broad bands centered approximately at 400 and $800 \mathrm{~cm}^{-1}$ and two intense bands located at 270 and $555 \mathrm{~cm}^{-1}$. Clearly, this spectrum is different from the one obtained in the germanate glasses with the same nominal composition, see our Fig. 4, probably due to the fabrication method. Lead-germanate glasses were produced by the melt-quenching method, while the lead-germanate thin film is grown on a silicate substrate through the rf-sputtering technique, using the vitreous target prepared in the following way: the oxide powders were mixed and then submitted to 8 tons of uniaxial pressure followed by the synthesis at $750^{\circ} \mathrm{C}$ for $10 \mathrm{~h}$.

The broad band centered at $385 \mathrm{~cm}^{-1}$ in the GP thin-film can be associated to the band detected at $458 \mathrm{~cm}^{-1}$ in the GP glasses, resulting in the symmetric stretching of the $\mathrm{Ge}-\mathrm{O}-\mathrm{Ge}$ bridgingoxygen bond. Henderson and Fleet [26] reported that the vibrational behavior of the $\mathrm{Ge}-\mathrm{O}-\mathrm{Ge}$ bond is complex and a slight variation in the $\mathrm{Ge}-\mathrm{O}-\mathrm{Ge}$ mean interhedral angle, $\phi$, or in the dihedral tilt angle, $\delta$, could generate sharp bands within a broader band structure. Furthermore, a decrease in the $\mathrm{Ge}-\mathrm{O}$ force constant, which occurs as a result of a lengthening of the
$\mathrm{Ge}-\mathrm{O}$ bond, leads to high frequency vibrations shift to lower frequency. Certainly, in the GP thin films studied these alterations were provoked by the stacking of atoms made by the method of physical vapor deposition.

There is no significant change in the position of the bands that confirm the presence of lead oxide $\left(100 \mathrm{~cm}^{-1}\right.$ and $\left.800 \mathrm{~cm}^{-1}\right)$ in the GP glass and GP thin film Raman spectra, but is easy to see an asymmetry in the band at $800 \mathrm{~cm}^{-1}$ in the second spectrum. This asymmetry is more evident in the spectrum obtained with the argon laser excitation at $488 \mathrm{~nm}$ (Fig. 5a), due to the resonance with the silver plasmon energy. Based on parameters presented by the Ribeiro et al. [25] it was possible to adjust five Gaussians to the profile of the band at $800 \mathrm{~cm}^{-1}$. The results are presented in Fig. $5 \mathrm{~b}$. The Nuclear Magnetic Resonance notation was adopted, where $\mathrm{Q}^{\mathrm{n}}$ $(0 \leq \mathrm{n} \leq 4)$ refers to different types of tetrahedral containing $n$ bridging oxygen. The Gaussians adjusted at 765 and $796 \mathrm{~cm}^{-1}$ are assigned to $Q^{2}$ species while the Gaussians at 720 and $875 \mathrm{~cm}^{-1}$ refer to $\mathrm{Q}^{0}$ and $\mathrm{Q}^{4}$ tetrahedra, respectively. The $\mathrm{Q}^{3}$ tetrahedra are identified by the Gaussian found at $835 \mathrm{~cm}^{-1}$.

The identification of two other bands, at 270 and at $550 \mathrm{~cm}^{-1}$, discloses the reaction of the GP film with the substances in the air during the manufacturing process. The first band is the result of the chemical adsorption of carbon dioxide onto the surface of silver, corresponding to the vibration of $\mathrm{Ag}-\mathrm{OCO}_{2}$ binding [28]. Chemical adsorption or chemisorption means adhesion of molecules from a fluid to a solid surface. The formation of the carbonate species on silver by this procedure has been demonstrated by several authors $[29,30]$. The second band indicates the stretching of $\mathrm{Ge}-\mathrm{OH}$ in a crystalline structure, more specifically, in the crystal $\alpha-\mathrm{GeO}_{2}$ type quartz $[31,32]$.

\section{Conclusions}

Microscope images showed that spherical silver NPs were formed in germanate glass with average diameters of 5 and $10 \mathrm{~nm}$, after the thermal treatment at $420^{\circ} \mathrm{C}$ over two and $48 \mathrm{~h}$, respectively.

Even with a low concentration (fraction volume of $1.7 \%$ ), the presence of the silver particles of $10 \mathrm{~nm}$ diameter induced an increase of $20 \%$ in the thermal diffusivity of the germanate glass. Thus, the silver NPs, besides contributing to the luminescence of the RE ions and nonlinear optical improvements [3-8], also improve the thermal properties of the glass.

An additional result is that the thermal treatment undergone by the sample caused the breakage of 3-membered rings of $\mathrm{GeO}_{4}$ tetrahedra, as noted by the decrease in intensity of the band at $534 \mathrm{~cm}^{-1}$ in the Raman spectra. This modification also may have contributed to the thermal diffusivity. Nevertheless, future analyses are required to check this point comparing the thermal lens signal of samples thermal treated with or without silver NPs.

The vibrations observed in the Raman spectra of the thin GP film are different from those detected in the Raman spectra of the glass with the same composition, evidenced by the $458 \mathrm{~cm}^{-1}$ band shifts to lower wavenumbers $\left(390 \mathrm{~cm}^{-1}\right)$ and the asymmetry of the band at $800 \mathrm{~cm}^{-1}$. Such change is justified by the sputtering technique used in the fabrication of thin germanate films. In this technique, atom by atom is deposited on the substrate and new links are constructed in order to minimize the energy of binding.

The Raman technique was sensitive to the formation of small crystals of the $\alpha-\mathrm{GeO}_{2}$ type quartz (i.e., the stretching vibration of $\mathrm{Ge}-\mathrm{OH}$ in a crystalline structure), as well as was sensible to the process of adsorption of carbon dioxide onto the surface of the silver, identified by the narrow bands at 555 and $270 \mathrm{~cm}^{-1}$, respectively, in the Raman spectra of the germanate films. 


\section{Acknowledgements}

The authors acknowledge the financial support of the Brazilian agencies FAPEMIG, CNPq and CAPES.

\section{References}

[1] T.A.A. de Assumpção, D.M. da Silva, L.R.P. Kassab, J.R. Martinelli, C.B. de Araújo, J. Non-Cryst. Solids 356 (2010) 2465-2467.

[2] T.A.A. Assumpção, L.R.P. Kassab, A.S.L. Gomes, C.B. de Araújo, N.U. Wetter, Appl. Phys. B 103 (2011) 165-169.

[3] G.H. Silva, D.P.A. Holgado, V. Anjos, M.J.V. Bell, L.R.P. Kassab, C.T. Amâncio, Richard Moncorgè, Opt. Mater. 37 (2014) 281-286.

[4] A.P. Carmo, M.J.V. Bell, Z.M. Da Costa, V. Anjos, L.C. Barbosa, E.F. Chillcce, J.M. Giehl, W.M. Pontuschka, Opt. Mater. 33 (2011) 1995-1998.

[5] A.P. Carmo, M.J.V. Bell, V. Anjos, R. Almeida, D.M. Silva, L.R.P. Kassab, J. Phys. D: Appl. Phys. 42 (2009) 155404.

[6] D.M. Silva, L.R.P. Kassab, S.R. Lüthi, C.B. de Araújo, A.S.L. Gomes, M.J.V. Bell, App. Phys. Lett. 90 (2007) 081913.

[7] L.R.P. Kassab, D.S. Silva, R. Almeida, C.B. de Araújo, App. Phys. Lett. 94 (2009) 101912.

[8] C.B. de Araújo, T.R. Oliveira, E.L. Falcão-Filho, D.M. Silva, L.R.P. Kassab, J. Lumin. 133 (2013) 180-183.

[9] C.C. Yang, J. Armellin, S. Li, J. Phys. Chem. B 112 (2008) 1482-1486.

[10] P. Keblinski, J.A. Eastman, D.G. Cahill, Mater. Today 8 (2005) 36-44.

[11] Jun Shen, Roger D. Lowe, Richard D. Snook, Chem. Phys. 165 (1992) 385-396.

[12] L.R.P. Kassab, M.E. Camilo, C.T. Amâncio, D.M. Silva, J.R. Martinelli, Opt. Mater 33 (2011) 1948-1951.

[13] X. Zhang, H. Gu, M. Fujii, Exp. Therm. Fluid Sci. 31 (2007) 593-599.
[14] J.C.S. Moraes, J.A. Nardi, S.M. Sidel, B.G. Mantovani, K. Yukimitu, V.C.S. Reynoso, L.F. Malmonge, N. Ghofraniha, G. Ruocco, L.H.C. Andrade, S.M. Lima, J. NonCryst. Solids 356 (2010) 2146-2150.

[15] S.M. Lima, J.A. Sampaio, T. Catunda, A.C. Bento, L.C.M. Miranda, M.L. Baesso, J. Non-Cryst. Solids 273 (2000) 215-227.

[16] L.M. Moreira, E.A. Carvalho, M.J.V. Bell, V. Anjos, A.C. Sant'Ana, A.P.P. Alves, B Fragneaud, L.A. Sena, B.S. Archanjo, C.A. Achete, J. Therm. Anal. Calorim. 114 (2013) 557-564.

[17] I. Maasilta, A.J. Minnich, Phys. Today 67 (2014) 27-32.

[18] V. Juvé, M. Scardamaglia, P. Maioli, A. Crut, S. Merabia, L. Joly, N. Del Fatti, F. Vallée, Phys. Rev. B 80 (2009) 195406.

[19] D.G. Cahill, et al., Appl. Phys. Rev. 1 (2014) 011305.

[20] A. Céreyon, B. Champagnon, V. Martinez, L. Maksimov, O. Yanush, V.N Bogdanov, Opt. Mater. 28 (2006) 1301-1304.

[21] G.S. Henderson, J. Non-Cryst. Solids 353 (2007) 1695-1704.

[22] A.O. Ivanov, K.S. Evstropiev, Dokl. Akad Nauk. SSSR 145 (1962) 797.

[23] M.K. Murthy, J. Ip, Nature 201 (1964) 285-286.

[24] R. Vijay, P.R. Babu, V.R. Kumar, M. Piasecki, D.K. Rao, N. Veeraiah, Mater. Sci. Semiconduct. Proc. 35 (2015) 96.

[25] S.J.L. Ribeiro, J. Dexpert-Ghys, B. Piriou, V.R. Mastelaro, J. Non-Cryst. Solids 159 (1993) 213-221.

[26] G.S. Henderson, M.E. Fleet, J. Non-Cryst. Solids 134 (1991) 259-269.

[27] E.A. Carvalho, A.P. Carmo, M.J.V. Bell, V. Anjos, L.R.P. Kassab, D.M. Silva, Thin Solid Films 520 (2012) 2667-2671.

[28] G.I.N. Waterhouse, G.A. Bowmaker, J.B. Metson, Appl. Surf. Sci. 214 (2003) 36-51.

[29] B. Krenzer, L. Constant, H. Conrad, Surf. Sci. 443 (1999) 116-124.

[30] K.J. Maynard, M. Moskovits, J. Chem. Phys. 90 (1989) 6668.

[31] D. Di Martino, L.F. Santos, A.C. Marques, R.M. Almeida, J. Non-Cryst. Solids 293 (2001) 394-401.

[32] W. Wu, X. Zou, Q. Li, B. Liu, B. Liu, R. Liu, D. Liu, Z. Li, W. Cui, Z. Liu, D. Li, T. Cui, G. Zou, J. Nanomater. (2011) 841701, doi:http://dx.doi.org/10.1155/2011/841701. 